\title{
Tactual size perception with the method of magnitude estimation
}

JON E. ROECKELEIN, Arizona State University, Tempe, Ariz. 85281

Three experiments which employed the psychophysical method of direct magnitude estimation were conducted in order to scale the stimulus dimension of size via active touch perception. Power functions were adequately fitted to the data for both one-trial and multi-trial presentations of an assigned modulus. Results obtained when Ss provided their own primary modulus were characterized by small, nondiscriminating ranges of size estimation. Various sensing and exploring movements made by Ss during the active touch perception tasks were discussed.

Studies of tactual size and shape perception by active touch may involve visual-tactual matching operations (e.g., Gibson, 1962; Rock \& Victor, 1964) or may employ some type of discrimination or learning task which completely excludes visual cues from the experimental procedure (e.g., Vekker \& Lope, 1961; Arana \& Sokolov, 1962; Over, 1966; Lobb \& Friend, 1967). In the latter studies, the discrimination tasks typically contain so-called "indirect" psychophysical designs; for example, some form of the method of constant stimulus differences is popular.

The psychophysical methods of direct magnitude estimation and absolute judgment have been employed both in visual size perception studies (e.g., Nesmith \& Rodwan, 1967), and in tactual perception studies dealing with stimulus dimensions such as roughness-smoothness (e.g., Stevens \& Harris, 1962). However, the tactual perception of the dimension of size or shape using the method of magnitude estimation and excluding Ss' visual cues has not yet been explored. The purpose of the present study was to scale tactual size perception by using the method of direct magnitude estimation within an active touch, nonvisual, paradigm.

\section{Subjects}

$$
\text { METHOD }
$$

Twenty-two students in an introductory psychology course served as Ss. None had served in an experiment previously.

Stimulus Objects

The stimuli chosen were two different sets of objects, Squares and Spheres. In the Squares category seven squares were cut from hard-rubber tile blocks in the dimensions, $3 \times 3 \times 1 / 8$ in., $3 \frac{1}{4} \times 3 \frac{1}{4} \times 1 / 8$ in., $3 \frac{1}{2} \times 31 / 2 \times 1 / 8$ in., $3 \frac{1}{4} \times 3 \frac{1}{4} \times 1 / 8$ in., $4 \times 4 \times 1 / 8$ in., $4 \frac{1 / 4}{4} \times 4 \frac{1}{4} \times 1 / 8$ in., and $4 \frac{1}{2} \times 4 \frac{1}{2} \times 1 / 8$ in. The Spheres category contained seven styrofoam balls having diameters of $1 \frac{1 / 4}{4}$ in., $1 \frac{1}{2}$ in., 2 in., $2 \frac{1}{2}$ in., 3 in., 4 in., and 5 in. The $3 \frac{3}{4} \times 3 \frac{3 / 4}{4} \times 1 / 8$ in. square was used as a standard for the Squares category, and the $2 \frac{1 / 2}{2}$. ball was used as a standard for the Spheres category.

Procedure

The stimulus objects in each set were presented one at a time to $S$ whose hands and forearms were placed through holes in a curtain which hung between $S$ and $E$. $S$ was allowed to handle each object with one or both hands on an average of 5-7 sec. Four samples of each object in each set were presented in a different order to Ss. Presentation of sets was also counterbalanced. Three experiments which employed the method of direct magnitude estimation were run, each with a different programming of the primary modulus. In the first experiment $(\mathrm{N}=10) \mathrm{E}$ assigned the number "ten" to the first stimulus and presented this "standard" stimulus before each of the other objects in the set. In the second experiment $(N=9)$
E assigned the number "ten" to the first stimulus; and, following this single exposure, the stimulus was withdrawn from the set. In the third experiment $(N=3) E$ did not assign a number to the first stimulus, but instructed $S$ to call the first stimulus by any number which he deemed convenient and appropriate. General instructions given to $S$ regarding his task conformed to instructions published by Stevens \& Harris (1962, p. 490), Stevens, Herrnstein, \& Reynolds (1965, p. 29), and Mashhour (1962, p. 258). The three experiments were designated as follows: Group 1 (Experiment 1, Assigned Modulus-repeated presentations), Group 2 (Experiment 2 , Assigned Modulus-one presentation), and Group 3 (Experiment 3, No Assigned Modulus).

\section{RESULTS}

The medians of the numbers assigned for the two sets of stimuli by the 19 Ss in Groups 1 and 2 are shown in Fig. 1 and Fig. 2. The inset equations in Fig. 1 and Fig. 2 are mathematical equations for the power functions that describe (a) the relationship between subjective and physical size in linear units, and (b) the relationship between subjective and physical size in logarithmic units.

Table 1 shows the size estimations for spheres and squares made by the three $S s$ in Group 3 who did not receive an assigned modulus from $\mathrm{E}$. It is apparent here that the range of estimations is rather restricted for both sets of stimuli and the overlap between estimations is noteworthy, occurring once for spheres and twice for squares. For this reason, a plot of the data contained in Table 1 failed to yield the type of power function which was obtained under the two Assigned Modulus conditions.

\section{DISCUSSION}

When comparing Fig. 1 with Fig. 2, it is apparent that it is not necessary to give an assigned modulus or standard stimulus before presenting each of the stimuli to be judged. E saves a considerable amount of experimental time by using this

PHYSICAL SIZE (P)

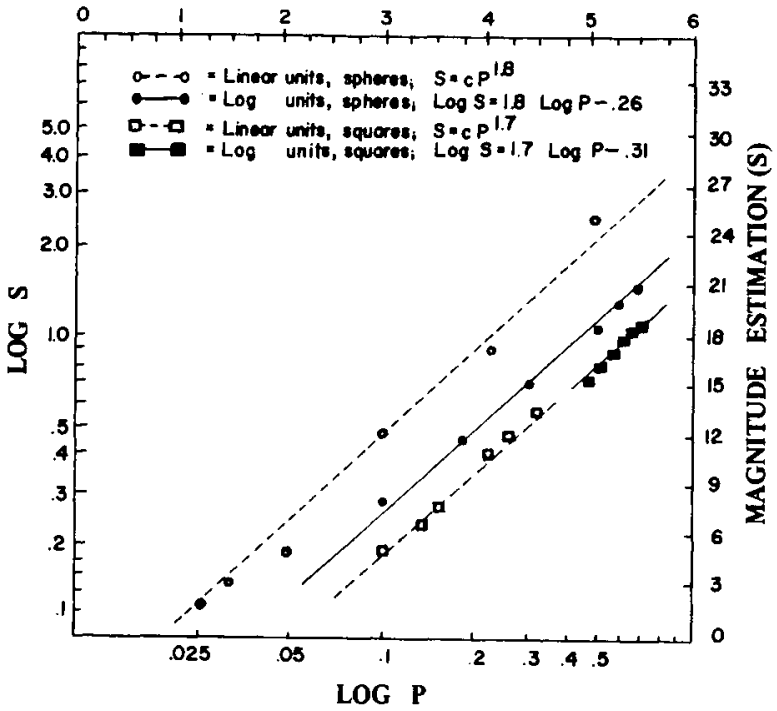

Fig. 1. The psychophysical magnitude function for size with an assigned modulus (repeated presentations) using active touch perception, plotted in terms of both linear (dotted lines) and logarithmic (solid lines) units. (Each point is based on 40 judgments- 10 Ss.) 


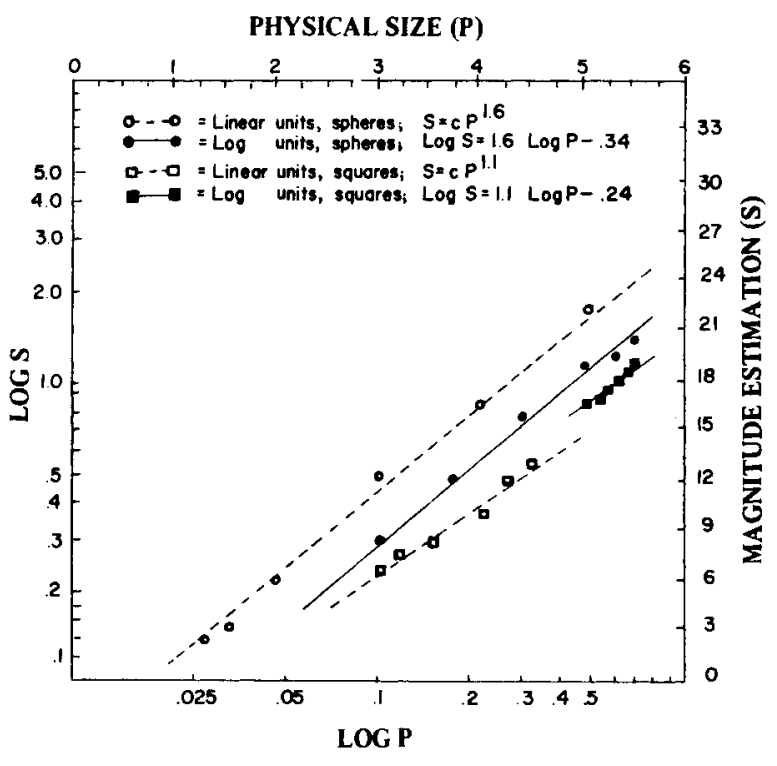

Fig. 2. Same as for Fig. 1, except the assigned modulus was presented only once at the beginning of the session. (Each point is based on 36 judgments-9 Ss.)

short-cut; S's boredom and fatigue are also decreased. This finding regarding tactual size estimation and the optimal experimental procedure for direct magnitude estimation is in agreement with other studies which recommend that only one, if any, designation of the assigned modulus be made (e.g. Stevens, Herrnstein, \& Reynolds, 1965, p. 29). However, it should be noted that some studies of direct magnitude estimation using a different sense modality, such as vision (velocity of oscilloscope spots), have deliberately programmed a standard stimulus before each judgment by $S$ (e.g., Mashhour. 1962).

The data from Fig. 1, Fig. 2, and Table 1 show, in a limited way, the effect of an assigned modulus vs no assigned modulus. While two highly similar power functions were fitted to the data generated by Groups 1 and 2 (Figs. 1 and 2), it is obvious from the lack of exclusiveness across estimations made by Group 3 (Table 1) that, when no modulus was assigned,

Table 1

Size Estimations without an Assigned Modulus fer Spheres and Squares from Three Ss Using Active Touch Perception

\begin{tabular}{ccccc}
\hline \multicolumn{2}{c}{ Spheres } & & \multicolumn{2}{c}{ Squares } \\
$\begin{array}{c}\text { Physical Units } \\
\text { (Inches) }\end{array}$ & $\begin{array}{c}\text { Subjective } \\
\text { Estimations }\end{array}$ & $\begin{array}{c}\text { Physical Units } \\
\text { (Inches) }\end{array}$ & $\begin{array}{c}\text { Subjective } \\
\text { Estimations }\end{array}$ \\
\hline 1.25 & 0.5 & 3.00 & 2.5 \\
1.50 & 1.0 & 3.25 & 2.5 \\
2.00 & 1.0 & 3.50 & 3.5 \\
3.00 & 4.0 & 4.00 & 3.5 \\
4.00 & 5.0 & 4.25 & 6.5 \\
5.00 & 8.0 & 4.50 & 7.0 \\
\hline
\end{tabular}

estimation points were relatively lower and more limited in range as compared with assigned modulus conditions. Allowing each $S$ to choose his own modulus apparently produces a "tighter" and "nondiscriminating" range for estimated size, at least for the two categories of stimuli used here. It is probable, though, that the small number of Ss used under the No Assigned Modulus condition imposed some restrictions on the present data. Thus, if further research using direct magnitude estimation of size yielded results similar to the one shown here, Stevens \& Harris' (1962) finding concerning the ineffectiveness of an assigned modulus would be disputable.

Informal records kept of Ss' hand movements and verbalizations showed that many Ss used their fingers in the manner of a ruler. That is, they regarded their forefingers as devices for setting off lengths on the stimuli or for pressing the edges of the stimulus into certain loci on the forefingers. These lengths and loci presumably acted as anchor points for judging subsequent stimuli. This observation may be compared with the "distinctive features" of Gibson \& Gibson (1955), the "scanning of vertices" of Lobb \& Friend (1967), and the "active-passive" distinction in touch made by Gibson (1962). Active touch perception does, indeed, seem to enlist some unique behavioral sequences for the sensing organism.

In summary, the results of the present study demonstrated similar and orderly power functions for size estimations via active touch when using two different categories of stimuli. The fact that highly similar exponents were derived for the different categories-categories whose own stimuli presumably contained attributes other than size (e.g., texture, weight, etc.) for Ss-attests to the strength of "size" as a variable operant in active touch perception.

\section{REFERENCES}

ARANA, L., \& SOKOLOV, E. N. The stochastic theory of perception Communication VIII. Effect of frequency of presentation on perception of figure. Doklady Akademii Pedagogischeskikh Nauk RSFSR, 1962, 4, 69-72.

GIBSON, J. J. Observations on active touch. Psychological Review, 1962 , $69,477-491$

GIBSON, J. J., \& GIBSON, E. J. Perceptual learning: Differentiation or enrichment? Psychological Review, 1955, 62, 32-41.

LOBB, H., \& FRIEND, R. Tactual form discrimination with varying size and duration of exposure. Psychonomic Science, 1967, 7, 415-416.

MASHHOUR, M. A comparison of the method of ratio estimation and the method of magnitude estimation. In J. R. Corso (Ed.), The experimental psychology of sensory behavior. New York: Holt, Rinehart, \& Winston, 1967. Pp. 258-260.

NESMITH, R., \& RODWAN, A. S. Effect of duration of viewing on form and size judgments. Journal of Experimental Psychology, 1967, 74, 26-30.

OVER, R. Context and movement as factors influencing haptic illusions. Australian Journal of Psychology, 1966, 18, 262-265.

ROCK, 1., \& VICTOR, J. Vision and touch: An experimentally created conflict between the two senses. Science, 1964, 143, 594-596.

STEVENS, S. S., \& HARRIS, J. R. The scaling of subjective roughness and smoothness. Journal of Experimental Psychology, 1962, 64, $489-494$.

STEVENS, S. S., HERRNSTEIN, R. J., \& REYNOLDS, G. S. Laboratory experiments in psychology. New York: Holt, Rinehart, \& Winston, 1965.

VEKKER, L. M., \& LOPE, YU. P. On the problem of the formation of tactual images. Voprosy Psikhologii, 1961, 5, 143-153. 